\title{
The Regeneration of a Silent Rural Community - Case Study on San Xing Community, Wujie Township, Yilan County
}

\author{
Mei-Jen Chi \\ National Chengchi University, Taipei City, Taiwan
}

\begin{abstract}
When the government implemented a series of land reform policies, take the "rural land owned by farmers and used as agricultural aims" as the core of agricultural land policy, and exactly make the farmlands to increase the quantity of crops and the peasants have raised their income. But let the rural communities gradually decline and the agricultural output value continued to decline; the rural population moved outwards. When the rural regions are in decline, which tend to experience high rates of unemployment and outmigration, how to develop the agriculture and countryside to maintain the vitality of rural community becomes the focus of government. This article is to explore the vitality of rural communities from the regeneration plan, selecting the Yilan County, Wujie Township, San Xing Community, and interviews with in-path interview about the problems and the view of community. Discuss with the rural community how to overcome the problems of the ever-changing social, economic, environment. In addition, provide some suggestions for the development of the rural community.
\end{abstract}

Keywords: rural communities, agricultural policies, rural regeneration

\section{Introduction}

Agricultural policies are the agricultural development plans or regulatory blueprints formulated to ensure the agricultural production \& economic development, and welfare enhancement for all citizens or farmers. These policies are usually implemented under the constraints of established systems, but may also be instituted under the committed revamp of the system (Kasper \& Streit, 1998). The so-called "system" can be defined as a set of formal and informal rules, and its enforcement arrangements. The purpose of setting the system is to guide individual behavior towards a specific direction or goal. Therefore the daily activities and social interactions are required as incentives for building the system, and precaution against the breeding of ambiguous system (North, 1990; Yan, 2010, p. 168).

After World War II, the rural production was crucial to the national survival; the agriculture industry was the mainstay of Taiwan's overall economic development. The first phase of land reform was therefore implemented from 1949-1953. Measures such as the 37.5\% arable land rental reduction, public land release, and land to the tiller were adopted to improve the agricultural structure, and promote agricultural development. However, the measures were solely for improving the production relations, enhancement of agricultural productivity, and transference of land capital to industrial capital. Though economic efficiency had been raised

Mei-Jen Chi, Ph.D. student, Department of Lands Economics, National Chengchi University, Taipei City, Taiwan.

Correspondence concerning this article should be addressed to Mei-Jen Chi, National Chengchi University, No. 64, Section 2, Zhi Nan Road, Wenshan District, Taipei City, Taiwan. 
too certain degree, the measures emphasized on distribution of land ownership that resulted in an under-scale and fractional productivity of cultivated land. With the industrial and commercial developments, there had been a widespread out flux of farming labor and non-fully engagement in tilling, but farmers were still reluctant to lease their unfarmed lands to others. These had led to a stagnant lease market for arable farmland and the perplexity in difficult expansion for farm business scale.

The expansion of the operational scale of farms was hindered by reasons namely as follows: limitation on identity transference for farmland that led to the gradual aging of agricultural business operators and low input of younger generations; stringent rules in classification of agricultural land that step up the complexity of land ownership relations; since the implementation of the $37.5 \%$ arable land rental reduction, a strict tenant protection policy had been adopted, strictly limited the landlords to terminate their leases, and thus nearly prohibited their chances of recovery of farmland. The impact was seen in the rigidity of arable land tenancy system that impeded farms' expansion of operational scale (Yan, 2001, p. 26; 2010, p. 169).

In view of this, the Executive Yuan approved, "the second phase of agricultural land reform program" in 1982 to increase farm business efficiency and reduce agricultural production costs, thus improving the agricultural structure and facilitating agricultural development. However, the expansion of farm scale depended merely on purchase of arable land; it was hard to raise funds to purchase land with limited loan amount. With the existence of $37.5 \%$ arable land rental reduction system, the implementation of entrust operation had cast uncertainties over the applicable provisions of the two systems, and held the farmers off with ineffectual identification costs induced. Moreover, the liquidity of arable land tenancy market would be affected by the inevitable increase in transaction cost during negotiations among multi-parties over the fractional arable lands. Due to the ineffectiveness of the program, since 1987, it has been in continuous implementation after being reviewed and incorporated into and continued for implementation under "The improvement program of agricultural structure to increase farmers' incomes" (Yan, 2010, p. 169).

Subsequently, with Taiwan's imminent accession to the World Trade Organization (WTO), adjustment of agricultural structure, improvement of production conditions were clearly imperative. Knowing the effectual implementation of the previous overly rigid agricultural policy, the government adjusted its policy guidelines and opted for "loosening the farmland ownership policy for farmers and actualization of farmers' ownership of farmland for farming purposes", in hope of keeping the basic principles of ensuring basic food security, maintaining agricultural development and natural ecological environment. Simultaneously, a detailed comprehensive review of "Agricultural Development Act" was conducted and amendments were promulgated on January 26, 2000, in which, to ease the farms' expansion of operational scale, measures covered such as a relaxation of free trading of agricultural land, and agricultural businesses may purchase agricultural land to facilitate input of funds and technologies.

Regulations were loosened on arable land division to reduce prolonged disputes, stipulations were set over the circulation of agricultural land use rights, and over the lease contract of arable lands after the law amendment, covering lease duration, rental, and payment mode set freely by the lessor and the lessee according to the contract, the rules were inapplicable to the $37.5 \%$ arable land rental reduction provisions. To reverse the already rigid tenancy system, the act mandated that the lessor do not need to pay compensation to the lessee for the recovery of farmland upon the termination of lease (Yan, 2001, pp. 26-27; 2010, pp. 169-170). 
Since the first implementation of land reform in Taiwan, the most noticeable impact on rural communities was the arousing of farmers until to motivation that led to a big leap in productivity per unit area. Yet the small-scale, fractional production of arable land has resulted in a host of problems such as small operational scale of farms, the impact of global trade liberalization, and the rival for agricultural land for non-agricultural activities. These led to the gradual loss of agricultural land, and damage to the agricultural production environment and in the end caused the desolate dwindling of rural communities and its development. To this end, agricultural department proposed in the 1990s the agricultural policies for three aspects: production, life, and ecology. Rural development was incorporated into the agricultural policy to seek for overall solutions to the aforementioned problems. Today's most representative policy is the rural community regeneration policy promoted in 2008, which shows the Taiwan's determination on overall rural development through legislation; however the effectiveness of this policy has yet to be tested.

In this article, use the literature analysis and in-depth interview as research approaches and take San Xing Community, Wujie Township, Yilan County as case study. It is for the understanding of the impact on rural communities and analysis of the discrepancies between the result of policies implemented and the targets set under the Taiwan rural community regeneration policies. In order to achieve sustainable rural development, and provide reference for Taiwan government's adjustments over agricultural policies and development of other rural communities, how the rural communities overcome problems caused by changes in social and economic conditions was also explored herein.

\section{Literature Review}

In order to establish the theoretical basis of the follow-up analysis of this article, we will review the relevant literatures of rural regeneration and understand the existing problems of rural rejuvenation and how these residents face the declined of community. The author has tried to look for the contribution of literatures in our aspects.

\section{Rural Development Process}

In Taiwan, the rural regeneration project ${ }^{1}$ was launched as one of I-Taiwan 12 Projects by Taiwan's President Ma Ying-Jeou (馬英九) after his assumption of the office in 2008. It was to address the hollowing-out of rural communities that gave rise to issues such as demographic aging in rural communities, out flux of young labor force, and depletion deficiency in software and hardware constructions. There had been rapid industrial changes and adjustments in rural development (from primary industry to secondary and tertiary industries). The drastic transformation in the industrial environment led to structural changes in industry, income, and population, resulting in the depletion of affluence in rural communities. To understand the multitude of predicaments in rural communities, we need to investigate how the various stages in rural development processes have impacted the agricultural production, living and ecological environment in rural communities. This paper then explores and analyzes the problems in rural developments in respect to economic, social, and environmental aspects.

\footnotetext{
${ }^{1}$ Rural rejuvenation policy guidelines, the last viewed date: 2019/11/5. Website: Soil and Water Conservation Bureau, Council of Agriculture, http://www.swcb.gov.tw/class2/index.asp?ct=Bulletin\&AutoID=475\&uT=Bulletin2\&m1=8\&m2=44
} 
The Taiwan's government began its first land reform from the 1949, such as "the 37.5\% Arable Land Rental Reduction"2 executed in 1949, the "Public land release"3 in 1951, and the "Land-to-the-Tiller" in 1953. By these measures, farmers' land ownership of self-farmed land was established to boost agricultural production, farmers' income and stabilize the political situation (Chen, 1961, pp. 79-88; Wu, 1981).

However, some scholars pointed out that the move would actually reduce rather than raise the farms' operational efficiency, as Jia-yia Hong (1990, pp. 5-1-5-4) pointed out that the $37.5 \%$ arable land rental reduction scheme did not carry any technical efficiency nor contribute to changes in economic efficiency. Hong-Jin Tsai (1997, pp. 33-67) pointed out that the rural land reform had numerous contributions to the agricultural industrial development such as: (1) Activate the farmers' operational motivation and free planning. (2) Promotion of precision utilization of rural land and labor force. (3) Government improved agricultural facilities and technologies accordingly. (4) Substantial agricultural production and sales growth. However, the reform left behind a host of agricultural problems such as: (1) Result in the structural defects as seen in scattered farmland and peasant agriculture. (2) Deficiency in agricultural capital and transference. (3) Overestimation of agricultural development after the land reform whose impact on development of agricultural industry construction was however ignored.

Tenant farmers have sprung to become the landowners after the first land reform. And then their income started to rise and could afford to pay their children's education, resulting in the first wave of emerging middle-class. Later, the government established the water irrigation facilities and farmers' organizations to back up the agricultural development. Farmers' associations provided technology of production and fertilizers to build up favorable development conditions for Taiwan's agricultural industry.

After 1960s, Taiwan developed the industries, as Ting-Hui Li (1980) said

Basically, Taiwan's economic development was a relative expansion of non-agricultural sector, and was the process of economic structural change, so the more rapid the economic developed; the greater the changes would be in the economic structure. That could easily end up in a dislocation between demand and supply by the agricultural and non-agricultural departments and a rival for utilization of resources. (p. 245)

\footnotetext{
2 The so-called " $37.5 \%$ arable land rental reduction" scheme was set based on the private farmland leasing regulations of Taiwan Province and its enforcement rule No. 2. The rental of arable land should not exceed the amount of $37.5 \%$ of the total annual harvest/three hundred seventy-five thousandths' annual harvest of the main agricultural products. The rental in the lease agreement exceeding this amount (375\%) will be deducted, but kept unchanged if the rental was below this amount. This reduction scheme took effect from April 1949 and the renewal of the contracts were mostly done by the second half of the year, affecting three hundred thousand renewal contracts and three hundred and seventy thousand total tenants which is $45 \%$ of the total farmers, involving the total land area of two hundred fifty-six thousand hectares that was almost equivalent to all the leased private land. Last visit date: 2019/8/16, http://ap6.pccu.edu.tw/Encyclopedia/data.asp?id=7551

3 The so-called "Public land release" (Sale of Public Land) was to sell public land to the farmers to create tiller households, and to replace the government-owned tenancy system by farmer-owned arable land system. That was one of the major features of implementation of the land to the tiller policy which were also demonstrations of rental reduction and a large number of private lands expropriation from the landlords for resale to farmers. Since the promulgation of "the act for fostering tillers by the sale of public farmland in Taiwan Province" and "the unemployment relief measures on sale of public land in Taiwan province", the actual sold area of public land was sixty-three thousand morgen since the implementation of sale of public land in 1951, where paddy field area was thirty-one thousand three hundred seventy-one morgen and dry farmland area was thirty-one thousand six hundred twenty-nine morgen. It generated one hundred twenty-one thousand nine hundred fifty-three household in total. Last visit date: 2019/8/16, http://ap6.pccu.edu.tw/Encyclopedia/data.asp?id=7551

${ }^{4}$ After the implementation of the land to the tiller policy which was the government policy of rental reduction and the sale of public land, government started to plan a full implementation of the policy "land to the tiller" in 1952. In the same year on January 20, Legislative Yuan approved the implementation of the land-to-the-tiller act and Bond of Taiwan Province Act. After works like propagandizing, supervision, and examination, government officially announced the expropriation and sale of leased private farmland to tenant families in May. Last visit date: 2019/8/16, http://ap6.pccu.edu.tw/Encyclopedia/data.asp?id=7551
} 
Zhenghong Liao, Chunchieh Huang, and Hsin Huang Hsiao (1986, pp. 6-11) believed that from 1953-1995, Taiwan's Agricultural Policy was featured with a called "suppressive development strategy", in which the government consistently optimized productions by the agricultural sector as the propelling power to support the industrial sectors. Yet, it became sign of future sluggish agricultural development in rural communities and the result of general farmland decay at a later time (Dong, 2009, pp. 82-90). The 12 years from 1968-1980 could be called the period of the agricultural recession, and uneven agricultural and industrial developments (Wu, 1993, pp. 385-387). To shorten the differences income gap between agricultural and non-agricultural sectors, from 1982-1991 resolutions were raised to adjust agricultural structure and nurture professional farmers to improve their income. Therefore in 1982, the "second phase of agricultural land reform act", was proposed, but it was just like a flash in a pan. But in the 1983, the U.S. requested Taiwan's government to reduce our rice exports.

In 1984, after the Sino-American treaty on rice export agreement, there has been a never-ending request by the U.S. for the opening up of Taiwan's domestic market of agricultural products. Taiwan's agricultural industry faced not only the technical issue but also the political and economic issues. Besides, at that time, there has been accelerated in trade liberalization internationally. Taiwan became an export-oriented country. This has brought about the increasing imports of agricultural products, pressure for domestic agricultural operations, and the rigorous challenges peasants need to face. At that time the agricultural sector had confronted with the three major issues: peasant agriculture adjustment, low prices of commercialized agricultural products, and the mastery of precise direction for agricultural policy decisions. These reasons caused the countryside to move towards recession.

Until the 1990, affected by trade liberalization, Taiwan was in application preparation to join General Agreement on Tariffs and Trade Pianxiang (GATT) ${ }^{6}$, and that casted even more severe impact on Taiwan domestic agricultural product. Due to fractional arable farmland and relative higher agricultural labor force, once Taiwan was open to agricultural imports, it placed itself in a disadvantageous position in sense of market price, and made many farmers suffer from grave reduction in income. Viewing the overall economic development track, the GDP total output value of the primary industry (agriculture, forestry, fishery, and animal husbandry) slid continuously from $7.26 \%$ in 1983 to only $1.9 \%$ in 2012 . The employed population of primary industry in the total employed population slid from $18.6 \%$ in 1983 to $5.0 \%$ in 2012, demonstrating a noticeable outflow of surplus labor force of agricultural sector in rural areas, and implied the outflow of rural population to urban areas. In respect to agricultural household income, according to the data in Agricultural Statistics Annual Report 2012, by the Council of Agriculture, in 1983 agricultural source of income of farm families accounted for $25.63 \%$ and non-agricultural income accounted for $74.37 \%$. The per capita income of each farm family earned only $72.22 \%$ of the non-farm families. That rate indicated this relatively low agricultural labor productivity and income level which adverse the agriculture and rural development.

\footnotetext{
5 Taiwan's Executive Yuan approved the "second phase of agricultural land reform program" in 1982, which aims were to improve the agricultural structure and promote agricultural development. The main contents were providing loans for land purchase, the redistricting of agricultural land (finished area: 70,674 hectares), the implementation of mechanized agriculture and the implementation of joint, entrusted and cooperative business operations to expand the scale of the farm operation. It showed that the focus of agricultural policy in that period was still on the adjustment of agricultural production structure and the operation mode to improve agricultural productivity for increase in farmers' income.

${ }^{6}$ In 1990, Taiwan applied to join the General Agreement on Tariffs and Trade Pianxiang (GATT), and then attended the meeting as an observer in 1992. After the establishment of WTO in 1995, Taiwan's applied to join WTO, and successfully accessed to it until January 1, 2002. Last visit date 2019/7/15, http://zh.wikipedia.org/wiki/\%E8\%BE\%B2\%E6\%9C\%83
} 
In addition, the high proportion of farmers' reliance on non-farm income emerges the decline in the importance of agriculture industry in rural areas, making for the direct and indirect severe out flux of rural labor force and the decline in the rural environment. Also it signified the rapid change respectively in agricultural and other form of industries, as well as the intense international competition in agricultural products Taiwan faced after its accession to the WTO in 2002. These all led to the lowering importance of agricultural production, and changes in production patterns and functions of the agricultural economy in rural areas. With the formation of Western diet culture and leisure living trend, the rice market shrank, agricultural industry shifted from the production pattern to other directions such as provision of the three regenerating business in the agricultural sector that concerns agricultural products, related leisure or ecology-focused agricultural services (Li, 2012, p. 77).

Because the economy and cities have changed the values of rural communities' residents, it weakens the residents' identity with their hometown and neighborhood relationship. As there was lack of community awareness and centripetal force that made enough public affairs participation, eventually it has resulted in a loss of traditional rural culture.

The industrialization and urbanization let the residents want to emulate the city. Yet, worsened by the lack of environmental aesthetics concept and inadequate participation in public affairs, there was a drastic loss of rural characteristics such as original spatial pattern, landscape, facilities and ecological environments, inducing the rural environment issues. Therefore how to strengthen the quality of rural human resources and appeal the inflow of quality city population are promoted the future sustainability and diversity in rural development.

The agricultural development, social structural changes, changes in patterns of land use have induced to the substantial changes in rural landscape, ecological environment, culture and society.

In the past, the government viewed the rural development as the urban development. This had ended in the improper planning for public facilities, and a corresponding lack of integration with the local features and cultural characteristics. Lateral transplants of public facilities in city pattern to rural areas were made. Myriad straight asphalt roads, cement paved square, monotonous and not distinctive public buildings were built. Architectural forms in rural areas were also similar to those in urban areas with monotonous two or three-floored buildings that came in flat-top reinforced cement, cement brick walks, parking space, and paved yard, making it hard to perceive the pastoral, rustic, and natural harmony in rural communities again.

The outflow of rural population has weakened the quality maintenance need and abilities for the upkeep public facilities and living environment. Moreover, local government is also constrained financially; construction of facilities for urban areas comes above rural communities' policies, leading to the relative insufficiency in construction, maintenance manpower, and funding of public facilities in rural area. Public facilities are at low service quality, and are caught in the vicious cycle of outflow of manpower, lack of incentives for industrial investment, and inadequate jobs opportunities.

\section{The Problem of the Rural Society}

In the past, Taiwan neither lacked the effective guides in planning act for rural planning, nor was there rural landscape management act to regulate the construction behavior in rural communities. Prior to 2009, there was no specific law to guide the planning of constructions in rural communities. Therefore, rural communities had to follow mainly the "non-urban land use management regulations" and "agricultural development act" as guidelines for its planning and spatial development. However, agricultural development act focuses on 
agricultural land management, failing to guide the substantial construction and development of rural communities, nor giving guidelines that involve land utilization, planning and construction management, landscape ecology and environmental protection, planning and initiation of public facilities in rural communities.

Issues such as narrow winding paths in alleys of early rural settlements, inadequate public facilities and poor drainage are all longstanding environment problems that cannot be solved. Due to complex land ownership and cadaster, coupled with outflow of population, the private residential housing has turned dilapidated without any management. All these contributed to the vicious cycle of poor living quality in rural settlements, out flow of population, and limitation over industrial development.

Rural developments involve various aspects such as agriculture, land, construction, resource management. It was under different units in the central and local government, confined by different legal stipulations. It is hard to have unified regulatory authorities; especially the insufficient funding and local administrative management manpower mean it is hard to have effective implementation of planning, construction, and management of rural communities. Since there is no responsible unit to coordinate the rural communities' construction, implementation and management works, the rural developments have become even difficult. How to address the disorderly development of rural phenomenon by rural development policy, regulations, and plan, and give effective guidance to the three regeneration projects (production, life, and ecological environment) in an overall development to actualize a new agricultural system are the important items in rural development for agricultural administrative units.

However, in face of globalization, the rebuilding of traditional rural communities is an important issue, therefore to how to promote the regeneration project for rural communities to enhance the overall development of rural communities and restore the pride of resident to fulfill the target of constructing a new wealthy rural community.

In 2008, the agricultural administrative units proposed "health, efficiency, and sustainable management" as the principal axis in agricultural policy that covers farmers, consumers, the environment, descendants, as well as the concern for the global world. There are several features in the regeneration act in rural community:

1. Focus on the existing agricultural rural community; make use of integrated planning concepts to strengthen the collective bottom-up participation and system.

2. Establish the overall regeneration in rural community, and stress the collective planning and establishment of agricultural industry, natural ecology, and living environment.

3. Emphasize the preservation and maintenance of rural culture and greening of rural landscape.

4. Consider the lack of rural building sites, propose plans such as incentive for absent landowners self-motivated planning of shared land or flexible management of land usage in the revamp of rural communities.

5. Promote consolidation and relocation of agricultural land by redistricting rural community and surrounding rural land to activate the utilization of rural land.

6. Encourage the establishment of the community convention and architectural style with local characteristics to create pleasant environment for rural areas.

Above is explication of the rural regeneration policy and meaning of the relevant act. The design of policy concerns the overall improvement plan for rural area development, and also hides rural land usage issues. It is hoped to flexibly manage the approved rural regenerated land to resolve the illegal usage of land. But the 
government avoided beyond current land use ordinance; the rural regeneration regulations have not dealt with rural land renewal issues. But this connotation of the law is significantly different from the rural renewal in other countries.

\section{The Problem of the Rural Regeneration Policy}

The government promoted the rural regeneration policy, using the collective bottom-up participation strengthened. Rural communities are encouraged to integrate organizations of rural community to propose the vision, targets, and idea of the rural regeneration project. They accorded to these residents' needs and wishes, and referred to the local government's plan on overall regeneration of rural areas.

The local government involved these rural regeneration plans with rural community together. They plan to include the community's overall environment, agriculture (fishing), construction of public facilities, infrastructure improvements, individual housing renovations, industrial activations, preservation and utilization of cultural and ecological conservation projects.

Residents of rural communities jointly developed rural regeneration plans for review by the county government. Upon approval, county (city) government will set the annual rural regeneration projects and apply for subsidies from the Council of Agriculture. One of the intentions of rural regeneration projects is to establish a bottom-up participatory system, and arouse people's concern for community-affairs so as to further achieve a sense of community cohesion. But the definition for the farming and fishing villages is still uncertain.

Of course, there are differences in farming and fishing village conditions. According to our country's definition of rural community, it "refers to the settlement of certain scale in a non-urban land and the incorporated area covered in result of the overall development needs of neighboring regions" ${ }^{\text {"7 }}$. If the content is vague with scope undefined, they will show no clear criterion for judgment. So defining the scope of agricultural and fishing villages to decide the eligibility in filing application for the regeneration project is a core of the regeneration project.

The agricultural authorities must review criteria for granting subsidies, even though the local government has approved the rural regeneration project and reached consistent agreement with the community organization over the approved item and budget within their jurisdiction of the regeneration project. As required by the law of Rural Revitalization Act, the rural community must propose the regeneration plan from the local organization. In addition, the organization must have its capability to integrate, propose, and implement rural regeneration plan. So, these communities must empower their residents to involve their local issues.

Besides raising the view passively in accordance with regulations, face any other remedy or access for appeal for farmers with different or opposite views. Although the government has huge budget, how to use these huge budget? Let the subsidies promote the rural community of ability and good-welling. Moreover, as required by law, the local governments review the rural regeneration proposal to upgrade their live, production, and environment. If the law does not have enough independence in review and cannot avoid the influence from local government, the rural community cannot to regenerate.

Most importantly, these subsidized items are lack of associations with agricultural production in rural regeneration projects. After all, the rural regenerations must base on the balanced development themes of "agricultural production, life and ecological environment", but not lost of balance by focusing on "life" only.

\footnotetext{
7 Rural Regeneration Act.
} 
However, agricultural authorities usually stress on hardware construction, neglecting the most crucial industry-agricultural industry. Agricultural industry is the source of income for farmers.

Although the majority of farmers do not fully engage in farming, and the agricultural authorities also hope to promote tourism and leisure industries in rural areas, each rural community has its geographical conditions, natural resources, human resources. That means there are heterogeneity and diversity in rural areas; the rural regeneration of rural development policy should support development of its characteristics. Agricultural businesses should be improved ecologically so as to avoid the environmental destruction of agricultural land. Then have it further developed to have characteristics of leisure tourism with traditional rural culture and lifestyle. The rural rejuvenated will then preserve the lifestyle that belongs to the residents, but also provide an excellent agricultural production base with quality ecological environment.

In the past, community building emphasizes self-motivated participation but except some active involvement from cultural workers and people that concern community affairs; residents from rural communities remain indifferent to the surrounding environment, showing low willingness of participation in public affairs. Due to today's competitive living conditions, people are getting distant from each other; rural community regeneration project hopes to elect a representative to propose the plan to the government, which will virtually create a negative experience, coupled with the aging rural population and inevitable different views of rural development; the rural regeneration project could set off the dispute in the communities $(\mathrm{Li}$, 2005, pp. 179-180). The community resources differ in each rural community, but how to and what is the development priority for the rural poor?

Secondly, traditional rural settlements are surrounded by a considerable amount of public land, and land and facilities of farmers' associations, irrigation association, and state-owned businesses. As the managing units have no sufficient fund and manpower, those lands are not utilized, managed and under long-term occupation lay idle to become unkempt spots in the community. Thus, the rural regeneration projects stipulate that those lands must be activated and re-used in line with the implementation need of the rural regeneration project. Land needs to be activated and re-used, to improve the overall quality of the environment in rural areas.

\section{Brief Introduction of San Xing Community}

This paper takes San Xing Community of Wujie Township, Yilan County as the subject of case study. The subject, San Xing Community mainly produces rice. The prosperous scene of rice production could be seen from the Barn of Erjie in Yilan, from where, rice was transported to other areas in early days. But this once vibrant rural community turned silent due to adjustment policies by agricultural sector-fallow farmland, reduced rice production, switch to other crops in arable land, and the out flux of labor force that led to the generally aging residents. Yilan County has limited fund on improving the rural environment; the agricultural development in rural communities and farmers' income are limited, resulting in inability to improve the social environment. But in recent years, due to traffic improvements, urban people have been bringing rapidly the urban perception into rural areas, and diluted the existing rural identity. In face of the incentive system in rural regeneration policies, the studied subject also hopes to restore the vitality and rich cultural life in rural areas through rural regeneration project.

How should the rural agriculture be activated? It should not be focusing on land activation only and abandon our excellent agricultural production base. The content of this paper is mainly about the approved rural communities for regeneration, through interviews to understand the implications of rural regeneration projects 
to residents there, so as to investigate if the rural regeneration policies can really bring about the balanced development of three regeneration businesses (agricultural production, life and ecological environment ) to the silent rural areas.

\section{Practice of the Rural Community Regeneration in San Xing Community}

Yilan County is located in the Northeastern Taiwan, with mountains on its three sides, Pacific Ocean on its east, and fertile Lanyang Plain (Yilan Plain) formed under the erosion of Lanyang River. It is one of the important agricultural counties in Taiwan of 2.6627 Esq. in area, with 727 households, totaling 2,164 people.

Since olden days, San Xing Village has been a typical agricultural village that focuses on agricultural industry, producing mainly rice. San Xing Village has its name originated from the morphing of one letter respectively from the village names of Fu Xing Village and second San Jie Village. The original expanse of Fu Xing Village is in the vicinity of Erjie Village's Xi Di Cheng (溪底城 Riverbed Town). Xi Di Cheng (溪底城 Riverbed Town) is somewhere along the North Road of Fu Xing Road (復興路). Xi Di Cheng (溪底城 Riverbed Town) gained its name from two stories. It is reputed that before the building of Lan Yang River (蘭 陽溪) dike, the village settlements nearby the Wang Sheng Temple were flooded with soaring stream water during typhoon seasons, turning itself into a riverbed.

Another similar story is that at the initial stage of development of Lan Yang, Lan Yang River was usually severely flooded that often caused the dike failures. Over time, it became a desolate land that the late developers had no more fertile ground to choose from but just made do to settle there. As developers gathered, a settlement was gradually formed and Xi Di Cheng (溪底城 Riverbed Town) was thus named from then on. Xi Di Cheng (溪底城 Riverbed Town) is still a common name in use, known as a typical rural settlement with most residents live by farming. However, as production environment changes, farming income can hardly maintain the basic household subsistence.

Therefore, with the major out flux of the residents, early traditional courtyard houses were left uninhabited and turned dilapidated. The rural community is in a bleak scene, with residents lacking faith in the community's future development. To rescue this vanishing settlement, in 2007, Da Er Jie Cultural Foundation (hereinafter referred to as "Foundation") strived to join the "The manpower training plan of rural regeneration" held by Ministry of Agriculture, Taiwan, SWCB (Soil and Water Conservation Bureau) Council of Agriculture. From caring class, advanced class to core class, the project along with the local residents participated in courses to discover the community resources and characteristics explore topics and proposals for solutions to community issues, and study and set the visions for the future rural community's regeneration. It is anticipated that through the regeneration project, the lost ecological, cultural, industrial, and self-confidence of the community can be restored and head for building a hopeful community that is full of stories.

The San Xing Community, like other rural communities, has gradually lost its agricultural productive function in result of changes in social and agricultural policies. Coupled with the opening up of Yilan National Freeway in rural areas, a further urbanization has been prompted. The overly urbanization also triggered the influx of city people into the countryside, who have accumulatively brought along the urban perspectives that have intensified the dilution of the sense of rural identity and its integral rustic role. "The manpower training plan of rural regeneration" the rural community regeneration project is for helping the residents there regain their faith and pride of their community. The San Xing Community residents are starting to participate in "The manpower training plan of rural regeneration" willingly and learn how to restore the fading out sound of rural community. 

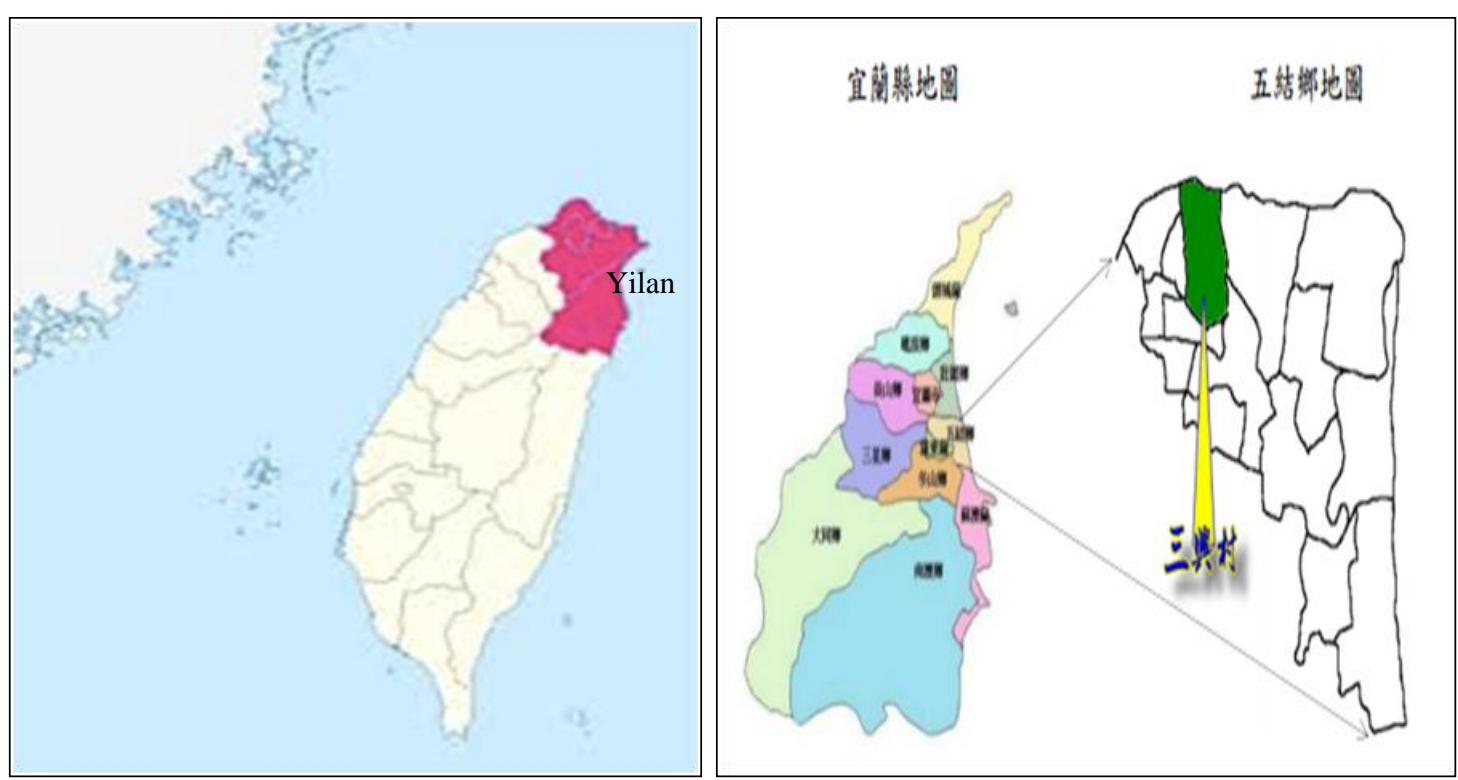

Figure 1. San Xing Community location map, Wujie Township. Source: Wujie Township Office.

Through activities, the "Foundation" will mobilize community residents to search for the original development trend and specialty resources, and manpower resources to rebuild the living cultures, history hall, local culture and history, folk customs and relevant rituals and ceremonies that originally belong to the rural communities. The purpose is to promote the residents' understanding and willingness of participation in the local development, foster the imagination and energy for symbiotic development, and empower the local residents. The daily, living experiences are sought after for conducting direct exchanges and sharing between the expertise and residents' regular experiences.

During the participatory process in community affairs and activities, through learning and taking actions, the San Xing Community residents have gradually started to show certain passion and care for their local affairs. From the past community to its today's regeneration, the community is no longer desolate and aims for finding back the fade-out sound of rural community.

What is that fading sound? It belongs to people, gongs and drums, and children laughter... we are all delighted when we heard a child's crying sound from certain family, for there has been no such sound for ages. (Respondent 1 )

Sound vanishes with the out flux of younger generation from the original community, therefore rural community regeneration policies are for revitalization of rural communities. Rural communities are not merely used as basis for the production of agricultural products; they should be an appealing living space in the countryside. Through the participation and compromises made by community's residents, the regeneration project is set for improving the fundamental production conditions within the rural community and maintenance of rural ecology and images. Chi Nan Chen, the former Chairman of Council for Cultural Affairs (Ministry of Culture) said:

Building a community is like building a temple in early farming communities. Villagers made use of their nightly spare time, gathered at the square in front of the temple to discuss the outlook and style of the temple, fund-raising and work distributions. Villagers share the money, efforts they could bear, totally free from reliance on governmental resources and assistance. The whole process took place according to one's most familiar and capable ways. 
Like early agriculture life in Taiwan, during Village Temple Fair for village gods, funds are collected according to the number of males and area of land of each household. There would be people who help neither arrange parade formation nor carry out religious ceremonies. Most residents in the community are involved in the process, thinking the ceremonies as an important event of one's family and part of the life throughout the year. It does not require special arrangements and mobilization, or changes in the way of life and habits, and of course, all is done out of sincerity in a habitual behavior but not based on consideration of material relationship.

San Xing Community respondents comment on some cultural heritages such as "Wanggong Temple", "Erjie Canal", and "Barn of Erjie Farmers' Association" within the community. It is believed that cultural heritages are a display of a way of life if they are released from a single base and isolated historical value; their layers of history and social context are compiled subsequently and instilled with local cultural energy. So the research interprets "regional/environment" that demonstrates cultural heritage as a flow not a form of living. "Preservation" is a remembrance or passing down of the past; "Revitalization" is a continuation or creation of the future; hence it is an incorporation of two aspects - concept and action-taking.

However, in the pursuit of modernity, the negative effects produced by discarding of local characteristic, monotony, commercialization, standardized production and overly development have in reality, severely suppressed the various possibilities for cultural heritage preservations and revitalizations. That may constitute the reason why Taiwan cultural heritage preservation has been focusing on the structural repairs, landscape maintenance, consistently promotion of tourism, and setting up some unknown café, restaurants, arts, and display space around cultural heritages. (Respondent 1)

Taking the Erjie "Wanggong Temple" as an example, which has been an important belief in Yilan, it is a masterpiece by traditional craftsmen Kavalan II. Though it does not have long history, it represents as an item of an era and witnesses a period of time in history. To preserve the look of the old temple, and allow the continuation of the residents and believers' emotional connection with "Wanggong Temple", the old temple of Erjie "Wanggong Temple" was moved horizontally for rebuilding into a new temple. Preservation of the old temple means retaining a shared memory for all and building a bridge for the continuation of tradition from modernity.

To match with the temple moving activities, there was an exhibition on "The Nostalgic New Temple" and invited performances by community folk arts groups and local school communities. These activities were an integration of religious faith, community humanities, and performing arts. (Respondent 2)

Later, a program on "Join in carrying stones for temple-building" was held to let the community residents to participate local affairs by mobilizing them to carry stones in relay to lay the foundation of the new temple. Whether the "Relocation of Temple by thousand people" or "Join in carrying stones for temple-building", it concerned not only the relocation of a temple, but the continuation of shared memory for the community residents. Erjie Canal is one of the important landscapes in San Xing Community. Chairman of the Foundation mentioned:

Sweet memory came into my mind whenever I think about playing at Erjie Canal or the moments when fish and shrimps swimming leisurely. Starting from unknown time, Erjie Canal was surrounded by U-shaped cement ditch; there was no traces of fish and shrimps and affinity between man and rivers.

I was then astonished to notice this and decided to approach the county government to help return the water space to the next generation. I led villagers to build the community. The first step began with landscaping. Under the efforts of everyone, willows were planted along the Erjie Canal, U-shaped ditch was gradually broken, and stream water has been drained into the primary school, creating an actual ecological education environment. 
Although Erjie is a small village with poor socio-economic conditions, in order to attract residents to participate in community activities, we must find ways to make residents come out and engage in community building. During the community building in the past, there was lucky-draw for Mid-Autumn Festival for villagers to participate. When the villagers come to understand the spirit of community-building community spirit, the festival activity was changed to poetry and music games. By the third year, to celebrate the festival, a carnival of "bringing our own dishes!" was held to invite the solitary elderly villagers to participate. Through a big reunion, the villagers learned to share and care for each other.

After a few years' community building events, Erjie residents have reached community consensus and local identity. They feel responsible for local affairs; through learning and participations, they understand group interest should be placed above individual interests. This concerns organization leaders who need to understand the thinking of residents, and through a variety of activities to keep residents enthusiastic about local affairs.

The grocery run by Mr. Zhi Wen Cai was located 500 meters away from the rear of Erjie Wonggong Temple. The house is 40 years plus; in the early times, it was once lived by no less than 15 people in the Cai family. The Cais lived very close to Wonggong Temple. When baseball was prevalent, neighbors would gather at Wonggong Temple to watch the game or Taiwanese opera. Though people had TV by then, there was a shared memory of watching TV together at Wonggong Temple. The temple courtyard was used as a baseball field and the temple as the shelter during typhoon days. In fact, the grocery displays the early bowls and dishes of early Taiwan; the rustic furnishings in the store will let tourists understand more about this Da Erjie area. Community residents all enjoyed milling about or chatting there about the peaks and bits of life in the olden days in Erjie, slowly helping regain its role as a gathering place for all.

Chen's old house is located in the Erjie old town alley. It has preserved the architectural beauty of traditional abode. As the father and son of Chen's family were educated and well versed in literature, they kept lots of rare editions of ancient medicinal books, magazines, and Four Books and the Five Classics. In addition, their family farmed and ran a rice mill in early days, so lots of farming implements or living utensils were kept intact.

Erjie Paper Plant was established in the Japanese ruling period. Paper was closely related to the development of Erjie. In recent years, the plant was in decline under the pressure of internationally competitive market. To extend the relations between paper and the community life, the community started to hold paper-related courses in 2003, which include plant craft paper, rubbing, prints that build connections among humanities, architecture, environment, and life stories in Erjie for creative works. In order to further enhance the quality of Erjie paper art creation, the 11th warehouse will be used as the Museum of Da Erjie Paper Art. The museum on one hand will serve as the interactive creational space for retired staff from the paper plant and the nearby residents, while making itself an important tourist attraction in the community.

"The Barn of Erjie Farmers' Association, Wujie Township" is located on the south bank of the Lan Yang River, nearby the Erjie train station. In 1998, Yilan County Government decided to include "The Barn of Erjie Farmers' Association, Wujie Township", the only remaining barn architecture from the Japanese ruling period as a historic site, and that was a major turning point to the barn's fate. In 2009, the Yilan County Government entrusted the operation of ErjieBarn, which is the current Barn of Erjie Rice Farmers' Cultural Hall to Da Erjie Cultural and Educational Committee. Activities such as operations of catering business, exhibition, and interpretation on rural communities' heritage are aimed at revitalization of the community's cultural heritage. 
Since the Foundation is the promoter and implementer of the San Xing rural community regeneration project, the Foundation uses the venue of the Barn of Erjie Farmers' Association as the Foundation office to handle their existing affairs and keep close interactions with community residents, and that is very different from other communities.

San Xing Community is really quite rich in terms of cultural landscape, but not sufficient enough to bring back the far gone fading sound. Therefore the community residents hope that through the manpower training plan of rural regeneration to investigate the following topics to reach consensus gradually. During the process of locating the rural resources (rural landscape) of San Xing Community, after several rounds of discussion and exchanges on topics such as internal resources, living, production, and ecology, the following items are formulated namely, four major development zones, loop and inter-connected trails, spacing idea for divisions of regenerated rural communities, and software empowerment projects. Discussed issues are such as the followings:

1. The opinion about the farmland within the community.

2. Where are the idle houses/lands? Besides the public lands and private lands, include the lands currently in use but may be idle in the future.

3. Which areas are not easy for fire engines and ambulances to get in?

4. Where are the flooded areas?

5. Locate the trails worthy of learning experiences by cycling or hiking (Users can be schools for teaching purposes, tourists, community residents, and more routes can be designed).

6. The stops along the trails and the possible business ideas around those stops raised by the community.

7. The locations of public facilities that needs upgrading (major public service center).

8. Systemic facilities (e.g., small-scale learning rest stops).

9. Reinforcement of landscapes along loop trails (e.g., greenway, streets with features, old houses).

Through the community resources survey and community residents' participatory identifications over items such as community resource points, stops await improvements, and available idle space; we formulate various featured zonal themes within the planned scope, and further establish the core idea for the community regeneration.

It is obvious that the regeneration project of San Xing Community must first have a good production environment, followed by living and ecological environment. Yet from the topics discussed above, we learned that the residents do not pay attention to the understanding of production environment. Other items emphasize on residents' usages of public facilities. Was it related to the governmental subsidies (that contain economic incentives)? If the subsidies are properly used, it will have a positive effect on the community. Yet if it is used for profiting certain stakeholders, it will accelerate the decline of rural areas.

The rural communities regeneration of San Xing Community is mainly led by the Foundation, different from other rural communities that led by village head or chairman of community development association. In the case when community residents do not have complete information, the leading rural development associations are usually in information-wide advantageous position. This advantage produces self-profit making situations, and thus affecting the residents' decision of participation. Yet Foundation that leads the San Xing Community regeneration requests directors and supervisors to work without income, only one administrative staff is paid.

The Foundation leased the Barn of Erjie Farmers' Association via OT payment. Part of the catering and exhibition space contributes to the source of income; a part of the barn is used as the Foundation office, giving 
the Foundation a different role from other community leaders. The organization led by the Foundation provides the community residents with shared public facilities, and that is an incentive for increasing the residents' organizational identification with the foundation, unconsciously strengthening the leading power of the organization. The Foundation plays the role of collecting idea and mastering sufficient information in pursuit of collective interests.

The Foundation held meetings to gather the residents to reach consensus before setting the plan for rural community regeneration. Presently, through meetings before holding activities, potential organizations can be found internally that means the organization can supply the residents with beneficial public facilities and also avoid the appearance of opportunists. The rural community regeneration is for upgrading the entire rural landscape environment; some residents might just enjoy the benefit without paying any efforts. Therefore the organization uses the residents' participation at the meetings to express their needs, and tackle and meet their requirements. In this way, residents are attracted to involve in the discussion of the rural areas regeneration.

\section{Conclusions}

Before 1990, Taiwan's agricultural policy was mainly about using a variety of measures to improve the productivity of agricultural products (especially food) and farmers' income. There should have been a cause and effect between increase of agricultural productivity and farmers' income. Yet under the low food price policy and the pressure from the U.S. that allowed a lot of U.S. grain imports, even though there had been an increase in productivity of Taiwan agricultural foods, farmers' income did not improve (Wu, 1993, p. 389). Thus in 1984, the promotion of "paddy transference" was in fact a product of international political pressure. That is to say, prior to 1990, the practices of Taiwan agricultural industry and land policies were actually production-oriented.

The agricultural policy adopted a low food price and the "Paddy transference" policy disabled farmers' income from rising while the national development was shifted from agriculture to industry-oriented. Under limited resources, rural constructions were only for facilities such as farm roads and waterways for irrigation. The outflow of agricultural labor force led to the increase in the productivity cost of rural areas, with the conflicting industrial policies, contributing to today's miserable situation in rural communities. The reason for this outcome was that there had been too much emphasis on the extent of the contribution of an industry, coupled with past national policy that advocated "raising industries with agriculture, assisting agriculture with industries".

This policy extracted resources accumulated by agricultural industry for transference to industries that failed to give the immediate support to the agricultural industry after their take off. Moreover, the agricultural industry was once again sacrificed in trade liberalization. The government showed an intention of good will; however when exploring the meaning of the Act and the content of the proposed projects for rural regeneration, it was still all about some hardware-based constructions. In contrast with the legislative intention which states "to promote the sustainable development in rural areas, the activation of rural areas, the improvement of basic production conditions, the maintenance of rural ecology and culture, the enhancement of the quality of life and the building of new, wealthy rural communities", does it mean that the process of improvement in hardware construction is able to get an opportunity of promoting rural sustainable development? Moreover with the past redistricting plan for farmland, there should have been some improvement for the rural communities. Yet both aforementioned policies failed to achieve the aims. The improvement of basic production conditions without 
clear, proper adjustments or measures to resolve the marketing problems of agricultural products would mean the impossibility for improving farmers' live, not to mention the effective drawing of young people to engage in agricultural industry back at home.

The characteristics of agricultural industry have constrained its production, with many factors such as limited area of arable land, climate changes, high labor costs, unbalanced production and marketing, unstable price in agricultural products which are all unfavorable to efficient agricultural production. Therefore, rural regeneration policies should stress even more on the balanced development of the three regeneration points of "agricultural production, life and ecological environment".

However, the intention and meaning of the act have deviated from these three points. On review of the rural regeneration projects, the local competent authorities have also failed to understand that agricultural production is one of the life lines of rural communities and neglected the marketing problems of agricultural industry. If the agricultural production in rural areas had been prosperous and there had been improvement in farmers' income, the farmhouse would not have been miserable and all the households would have a tidy look. Therefore from the study of the subject in this paper, it is found that the focus of rural regeneration projects is still on hardware construction.

Although there is an elevation of cultural connotation, it is still inadequate for the transformation of agricultural industry into tourist industry. On the fourth year since the agricultural sector's proposal and implementation of the regeneration policy for tackling the rural issues, if there are still no concrete measures to resolve the marketing problem in agricultural products, how can the goals of balanced development of "product, life and ecology" be fulfilled? The rural regeneration policies will fall into the trap of activating the land by turning rural areas into the plight of leisure holiday spots for urban people.

\section{References}

Cai, P. H. (2009). The categorization of farmers under the agricultural restructuring differentiation (1980-2005) (Doctoral dissertation, Department of Bio-industry Communication and Development, College of Agriculture, National Taiwan University, Taipei).

Chen, C. (1961). Minutes of land reform in Taiwan. Taipei: Chung Hwa Book Co.

Dong, J. H. (2009). The dilemma of Taiwan's rural planning and regeneration - the refection on Taiwan's agricultural industry and rural development. Economic Outlook Bimonthly, 122, 82-90.

Hong Chin Tsai (1997). Changes in Taiwan's agriculture and rural life. Republic of China Farmers Group Cadre Joint Training Association. Taipei.

Jia-yia Hong (1990). Discussion on the efficiency of the three-seventh-five rent reduction policy. National Taiwan University. Taipei.

Kasper, W., \& Streit, M. E. (1998). Institutional economics: Social order and public policy. Cheltenham: Edward Elgar.

Li, C. J. (1995). The impact of land reform on the land distribution and problems generated. Land Economics Annual Publication, $6,157-174$.

Li, C. J. (June 2012). Agricultural land and rural development policy-the direction under the new agriculture. Taipei: Wu-Nan Book Inc.

Li, T. H. (1980). Economic analysis of Taiwan's agricultural development. Taipei: Linking Publishing Company.

Lin, P. L. (2010). The study on Taiwan's rural development and governance changes (Thesis, Graduate Institute of Urban Planning, National Taipei University, Taipei).

North, D. C. (1990). Institution, institutional change and economic performance. Cambridge: Cambridge University Press.

Ostrom, E. (1990). Governing the commons - the evolution of institutions for collective action. New York: Cambridge University Press.

Peng, M. H. (2011). Critical report on food crisis, Taiwan observation. Taipei: Business Weekly. 
Shen, X. Y. (Sherry), Chen, Q. R., \& Zhuang, Y. W. (March 2012). 100 years of agricultural essence-Taiwan agricultural centennial documentary. Agricultural Policy and Agricultural News, 237, 1-2. Retrieved from http://www.coa.gov.tw/view.php?catid=2445335 [last viewed date: $2014 / 1 / 5$ ]

Wang, J. H., \& Zhang, Y. J. (December 2007). From agricultural protection towards rural development-turning point of the EU Common Agricultural Policy. Agricultural Extension, Council of Agriculture, Executive Yuan: Window of Agriculture Column. Retrieved from http://agrext.coa.gov.tw/agrext/event01/epaper12/full.htm [last viewed date: 2018/1/5]

Wu, C. X. (1981). Land to the tiller and agricultural land use. National Taiwan University, Journal of Sun-Yat-Senism, 2, 9-16.

Wu, T. Q. (1993). Taiwan's agricultural history. Taiwan: Culture Publishing Company, Independence Evening Post.

$\mathrm{Wu}$, T. Q. (2005). The evolution of Taiwan's agricultural development policy. Research report, National Policy Foundation.

Xu, S. R., Lai, Z. Y., \& Yan, A. J. (2009). Rural regeneration is possible only after the activation of farmers' rural life. Liberty Times, $1 / 12$, A13.

Yan, A. J. (1986). Research on basic conditions and structural changes of Taiwan agriculture (Doctoral dissertation, Department of Land Economics National Chengchi University, National Chengchi University, Taipei).

Yan, A. J. (2001). Interpretation of the future agricultural land use and management from the enacted amendments of agricultural development act. The Quarterly Journal of the Land Bank of Taiwan, 38(3), 25-43.

Yan, A. J. (2010). Critical analysis of Taiwan's small landlord, big tenant policies from institutional perspective. In Y. Xu and Y. M. Zhao (Eds.), Land transfer and rural governance - research on both sides (pp. 168-212). Beijing: Social Sciences Academic Press. 